\title{
Penn State Meeting Probes Materials Synthesis Needs
}

\section{Experimental Meeting Format Uses Satellite TV}

June 11-13, 1990 saw an experiment in the conduct of scientific meetings, organized by Pennsylvania State University's Materials Research Laboratory (MRL) with Office of Naval Research support. The subject-the science of materials synthesis-was recently identified by the U.S. National Academies' MS\&E report as this country's biggest deficiency in materials science and engineering.

The experiment included a limited onsite audience supplemented by satellite TV telecasting (through National Technological University), and featured three days (18 hours) of invited talks by many of the world's most successful synthesizers of useful materials. Despite the mailing of about 20,000 announcements of various kinds to selected university departments, industries, etc., on-site attendance was low (less than 125) and only 10 remote TV sites participated.

The meeting, however, proved to be a collection of excellent papers on the stateof-the-art of materials synthesis and fruitful discussions on what science is needed to accomplish this effectively.

Presentations spanned the following: "Science Needed for Synthesis" by R. Roy (Pennsylvania State University); "Diamonds-High Pressure and CVD Methods" by R.C. DeVries (General Electric); "III-V Semiconductors" by T. Nakahara (Sumitomo Electric); "Ceramic Alloys (Sialons)" by K.H. Jack (Newcastle); "Microbiosensors" by I. Karube (University of Tokyo); "Glass Ceramics" by George Beall (Corning); "Electroceramics" by L.E. Cross (Pennsylvania State University); "Chemically Bonded Ceramics" by David Double (Alcan International); "Microporous Materials Including Zeolites and Pillared Clays" by David Vaughan (Exxon); "Directed Oxidation for Ceramic and Metal Matrix Composites" by Marc Newkirk (Lanxide); and "Nonstructural Nanocomposites" by R.E. Newnham (Pennsylvania State University)

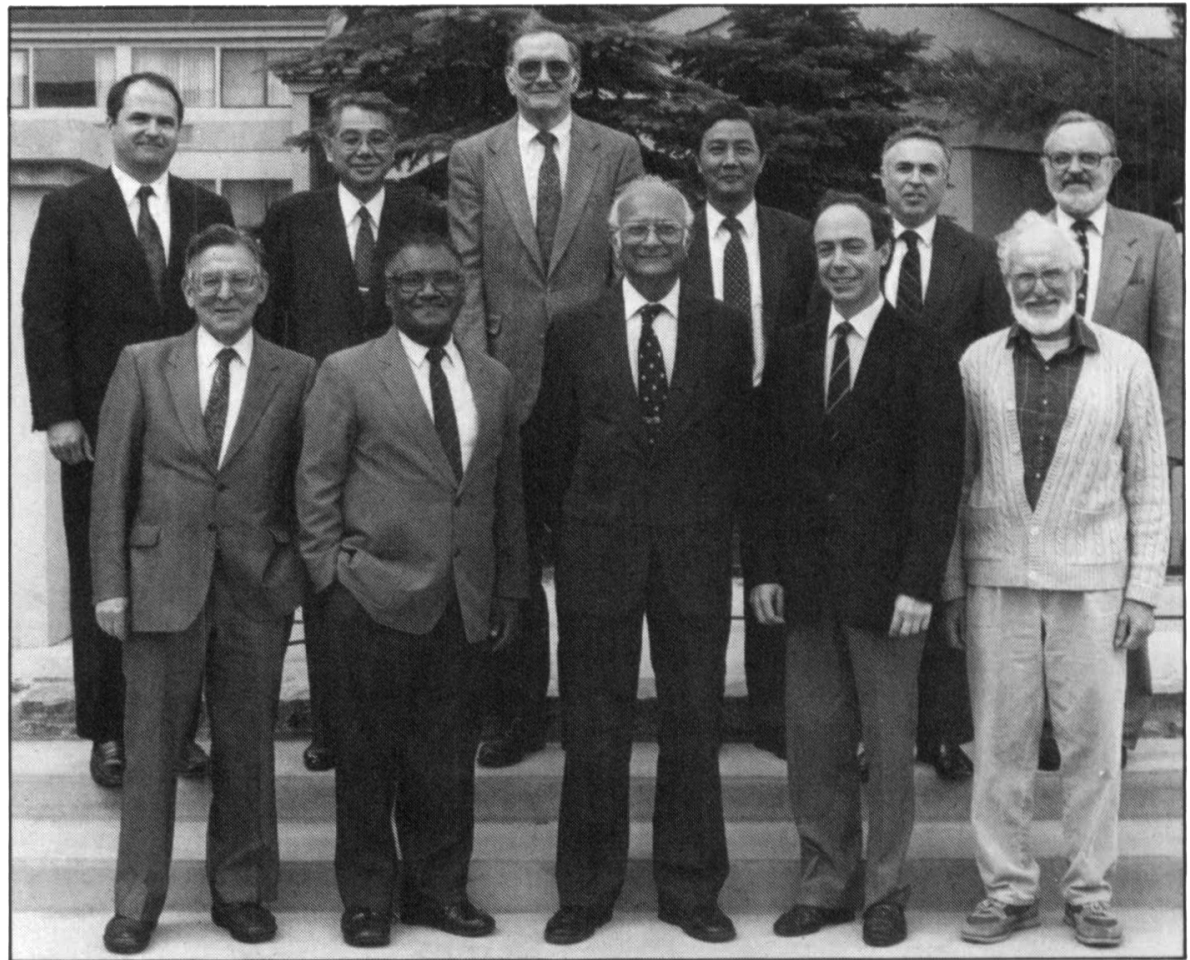

Invited speakers at the Science of Materials Synthesis meeting: (front row, left to right) K.H. Jack, C.N.R. Rao, R. Roy, D.D. Double, and R.C. DeVries; (back row, left to right) M. Newkirk, T. Nakahara, G. Beall, I. Karube, D. Vaughan, and L.E. Cross.

The discussions brought considerable consensus on the need for the following in institutions wishing to develop materials synthesis capabilities:

1. A solid grounding in the principles of crystal chemistry illustrated with examples from recent successful syntheses;

2. A thorough understanding of phase equilibria including polynary systems, elementary $\mathrm{p}-\mathrm{t}-\mathrm{x}$, and metastable equilibria,

3 . Access to equipment for synthesizing the processing covering the $\mathrm{p}$-t range 0 $3000 \mathrm{~K}, 0-100 \mathrm{kbars}$, including CVD and PVD; and
4. A sufficient synthesis and characterization experience within the team to permit serendipitous observations.

The papers will be published as a Festschrift volume honoring Prof. Rustum Roy in his 65th year; the TV tapes and the paperback text will be made available for use in courses on materials synthesis by the Materials Education Council. For information contact: Robert Berrettini, Materials Education Council, 110 Materials Research Laboratory, University Park, PA 16802 4801.

\section{MRS Fall Meeting - November 26 - December 1 - Boston}

